\title{
Raffaella SARTI (dir.), Lavoro domestico e di cura : quali diritti?
}

Rome, Ediesse, 2010, 369 p.

\section{Anna Bellavitis}

\section{(2) OpenEdition}

Journals

Édition électronique

URL : http://journals.openedition.org/clio/10911

DOI : $10.4000 /$ clio. 10911

ISSN : 1777-5299

Éditeur

Belin

Édition imprimée

Date de publication : 31 décembre 2012

ISSN : 1252-7017

Référence électronique

Anna Bellavitis, "Raffaella sartı (dir.), Lavoro domestico e di cura : quali diritti ? "Clio. Femmes, Genre, Histoire [En ligne], 36 | 2012, mis en ligne le 19 avril 2013, consulté le 22 septembre 2020. URL : http:// journals.openedition.org/clio/10911; DOI : https://doi.org/10.4000/clio.10911

Ce document a été généré automatiquement le 22 septembre 2020.

Tous droits réservés 


\title{
Raffaella SARTI (dir.), Lavoro domestico e di cura : quali diritti?
}

Rome, Ediesse, 2010, 369 p.

\author{
Anna Bellavitis
}

\section{RÉFÉRENCE}

Raffaella SARTI (dir.), Lavoro domestico e di cura : quali diritti ?, Rome, Ediesse, 2010, 369 p.

1 L'Italie est l'un des pays de l'Union européenne où l'on fait le moins d'enfants, où le pourcentage de personnes âgées de plus de 65 ans est parmi les plus élevés (en 2008 , Italie : $20 \%$; Europe à $25: 17 \%$ ), et où la dépense publique pour l'assistance aux personnes âgées est parmi les plus basses (en 2006, Italie : un peu plus de 0,1\%; Europe à 25 : un peu moins de $0,5 \%$,). Quel est alors le secret italien ? Le " welfare fait maison », c'est-à-dire une troupe d'assistantes domiciliaires payées par les familles et, en grande partie, composée d'immigrées clandestines d'Europe de l'Est, que l'on appelle les badanti («celles qui s'occupent de...»). Ce système original, qui a attiré l'attention des chercheurs au niveau international, a pu fonctionner pendant quelque temps, se fondant sur les déséquilibres internes à l'Europe. Il menace maintenant de s'écrouler, sous la double pression d'une demande croissante de droits et de meilleures conditions de travail de la part de ces travailleuses, et de la crise économique qui, d'un côté, diminue les ressources que les familles peuvent destiner à payer la badante et, de l'autre, pousse un nombre croissant de femmes italiennes, au chômage, à chercher une occupation dans le secteur de l'assistance à domicile. Il faut ajouter à cela, le développement économique dans les pays de départ - c'est le cas notamment en Roumanie - qui, à terme, pourrait être en mesure d'offrir des emplois qualifiés à ces femmes qui, très souvent, quittent leur pays après avoir fait des études et $\mathrm{y}$ avoir obtenu des diplômes, en y laissant leurs familles qui comptent sur leurs salaires de migrantes. Pendant quelques décennies, à cheval entre les $\mathrm{XX}^{\mathrm{e}}$ et $\mathrm{XXI}^{\mathrm{e}}$ siècles, on a donc assisté en Europe, mais de manière spécifique en Italie, à un phénomène de migration 
féminine qui a transformé des femmes, très souvent mères de famille, en breadwinners pour toute la famille restée au pays. Cela n'a pas suffi à modifier les relations et les hiérarchies à l'intérieur des couples et des familles d'origine, où, très souvent, les maris, restés au pays, sont soutenus, dans les tâches de soin et de garde de la maison et des enfants, par d'autres femmes de la famille.

' n' est qu'un des aspects traités par ce beau recueil, résultat d'une journée d'études, qui s'est tenue à l'Université d'Urbino-Carlo Bò, en 2008, à l'occasion du cinquantenaire de la loi 339 du 2 avril 1958, qui a réglementé en Italie le service domestique. La journée avait été organisée par Raffaella Sarti, spécialiste reconnue au niveau international de l'histoire du service domestique, et auteure de la Vita di casa: abitare, mangiare, vestire nell'Europa moderna, publiée en Italie en 1999, avec une préface de Jacques Le Goff, et traduit en plusieurs langues, mais pas en français.

3 Le volume rassemble les contributions d'historiennes, de juristes et de femmes qui, ayant été à leur tour employées dans le secteur, sont devenues des syndicalistes et activistes de la défense des droits des travailleuses dans le service domestique. La première partie, par Raffaella Sarti, est consacrée à une "vue d'ensemble » sur l'histoire du service domestique depuis l'Unité Italienne et jusqu'aux temps présents. On y découvre l'évolution d'une figure, la "servante", devenue COLF, acronyme de " collaboratrice familiale », une évolution sémantique qui correspond, certes, à une évolution de société : de la jeune fille venue de la campagne, qui réside avec ses maîtres et qui travaille 24 heures sur 24 , à la femme consciente de ses droits, qui ne travaille que quelques heures par jour et a une vie de famille. Persistent, toutefois, les ambiguïtés d'une relation, très personnalisée et quasiment intime, fondée sur le modèle de la relation de maître à serviteur. Et où, comme on l'a vu, le nouveau modèle de la badante vient compliquer le tableau. Une autre spécificité italienne qui apparaît dans la belle synthèse de Raffaella Sarti est l'augmentation parallèle, dans les années 1960-1970, de l'occupation féminine à l'extérieur de la maison et du nombre de femmes employées comme domestiques dans les maisons. À la différence des pays d'Europe du Nord, et notamment des pays scandinaves, où s'affirme progressivement un certain partage des tâches domestiques entre femmes et hommes, et où les services publics (crèches, écoles maternelles), mais, aussi, au-delà du service public, laveries automatiques, se chargent des tâches de soin traditionnellement confiées aux femmes, en Italie l'absence des femmes des maisons doit être remplacée par d'autres femmes, les domestiques.

Dans la deuxième partie du volume les « regards croisés » d'une chercheuse en sciences sociales, Claudia Alemani, de syndicalistes, Artemigia Ioli et Clorinda Turri, et de juristes, Luciano Angiolini, Franco Basenghi et Paolo Pascucci, proposent une analyse de l'évolution du statut du travail domestique dans l'Italie républicaine, à partir des luttes syndicales et de la législation. Il est évident que les spécificités de la relation de travail domestique ont des conséquences sur ses possibilités d'organisation syndicale, où ont joué un rôle déterminant les associations catholiques, et sur l'apparat législatif, dans la mesure où le législateur hésite à imposer aux employeurs les mêmes contraintes que dans d'autres sortes de relations de travail. C'est le cas, notamment, des lois sur la tutelle de la santé des travailleurs, qui excluent justement le travail à domicile.

Dans la dernière partie, consacrée au «travail domestique et de soin: nouveaux croisements entre public et privé », Elena Marchi, Flavia Piperno et Raffaella Sarti 
présentent une série de recherches sur l'assistance aux personnes âgées. On y apprend, entre autres, qu'il existe de notables disparités territoriales à l'intérieur de l'Italie, où certaines administrations régionales proposent des «chèques-soin ", selon la formule « cash for care ", destinés à permettre à des membres de la famille de s'occuper de leurs parents et/ou à payer du personnel à domicile. Bien évidemment, quand cette opportunité est saisie par des membres de la famille, il s'agit toujours des femmes, filles, sœurs, belles-filles, qui sortent ainsi du marché du travail. Le modèle badanti est, comme on l'a vu au début, en pleine évolution et peut-être aussi destiné à disparaître. Une politique active de gestion du care a un coût élevé et nécessite des choix clairs de la part des gouvernements, notamment en période de récession économique. Cependant, le "welfare fait maison» a aussi des coûts. Ce sont les coûts économiques du travail «au noir » et les coûts sociaux d'une mauvaise gestion des politiques d'immigration. C'est un défi complexe, qu'un pays comme l'Italie devrait, enfin, accepter de relever.

\section{AUTEURS}

\section{ANNA BELLAVITIS}

Université de Rouen 